\title{
Estimation of the Foliar Area by Non-Destructive Methods in Two Stages of Growth of Pepper Plants (Capsicum annuum L.) Hybrid Salvador
}

\author{
Osvaldo Fosado Téllez ${ }^{1}$, Emanuel Muñoz Muñoz ${ }^{2}$, Antonio Torres García ${ }^{1}$, \\ Jorge Luis Cué García ${ }^{3}$, Eduardo Fidel Héctor Ardisana ${ }^{1 *}$, Rolando León Aguilar ${ }^{1}$, \\ Elízabeth Fosado Obregón4
}

\author{
${ }^{1}$ Facultad de Ingeniería Agronómica, Universidad Técnica de Manabí, Portoviejo, Ecuador \\ ${ }^{2}$ Instituto de Ciencias Básicas, Universidad Técnica de Manabí, Portoviejo, Ecuador \\ ${ }^{3}$ Universidad Técnica del Norte, Ibarra, Ecuador \\ ${ }^{4}$ Departamento de Ingeniería Industrial, Universidad de Pinar del Río, Pinar del Río, Cuba \\ Email: *ehectorardisana@gmail.com
}

How to cite this paper: Téllez, O.F., Muñoz, E.M., García, A.T., García, J.L.C., Ardisana, E.F.H., Aguilar, R.L. and Obregón, E.F. (2018) Estimation of the Foliar Area by Non-Destructive Methods in Two Stages of Growth of Pepper Plants (Capsicum annuum L.) Hybrid Salvador. American Journal of Plant Sciences, 9, 325-338. https://doi.org/10.4236/ajps.2018.93026

Received: December 1, 2017

Accepted: January 29, 2018

Published: February 1, 2018

Copyright $\odot 2018$ by authors and Scientific Research Publishing Inc. This work is licensed under the Creative Commons Attribution International License (CC BY 4.0).

http://creativecommons.org/licenses/by/4.0/

(c) (i) Open Access

\begin{abstract}
The present work was aimed to obtain a model for the determination of the leaf area in function of the length and width of the leaves in pepper (Capsicum annuum L.) hybrid Salvador. The research was carried out in nursery conditions at the Experimental Campus La Teodomira, located in the parish of Lodana, Santa Ana, province of Manabí, Ecuador, in 2016, in the stages of initiation of flowering and flowering-fructification. In each phase 100 physiologically mature leaves of different sizes were collected. Leaves were digitalized in a rectangle with known dimensions, which allowed the area to be calculated through the percentage of pixels of different colors. From the determination of the length and maximum width of each leaf and the estimated area through the digitization process, the regression models were obtained, selecting the better fit generated between the leaf area and the product of the length by the maximum width of the leaf ( leaf area $=f\left(\right.$ length ${ }^{*}$ width $)$ ). In the initiation of flowering stage the quadratic model generated the best coefficient of determination $\left(\mathrm{R}^{2}=0.958\right)$, whereas in the flowering-fructification stage the best coefficient of determination was achieved by the cubic model $\left(R^{2}=0.955\right)$. The practical applicability of other simpler models among the tested ones, which show a high accuracy and sacrifice a low percentage of error, is discussed.
\end{abstract}




\section{Keywords}

Image Binarization, Regression Analysis, Leaf Area

\section{Introduction}

The determination of the foliar area is an important indicator for physiological, ecophysiological and agricultural investigations in the diversity of species of cultivated plants, given that growth, biomass synthesis by photosynthesis (absorption of $\mathrm{CO}_{2}$ and light), transpiration, consumption of water, mineral nutrition, respiration, production and quality of yield are directly related to the leaf area [1] [2]-[7].

Non-destructive methods for the estimation of leaf area, although dating from the last century, are still valid today, which has been demonstrated in Prunus persica L. Batsch and Prunus salicina Lindl. [2], Zea mays L. [8], Coffea arabica L. [7], Zingiber officinale L. [9], Alnus acuminata L., Escallonia pendula (Ruiz \& Pav.) Pers. and Quercus humboldtii Bonpl. [1]. These studies have shown that leaf length and width are effective variables for the estimation of the leaf area coefficient in different crops, despite the morphological differences of their leaf blades.

The main advantages of the use of allometric models for the estimation of the foliar area [6] [7] [8] are summarized in the following sections:

- These non-destructive models allow the measurement in vivo of plant leaves, being able to follow their evolution in the same leaf, which diminishes the variation substantially.

- The cost associated to equipment and human resources for measuring the leaf area is substantially reduced.

- If a reliable equation is selected, calculations can be made quickly and with great precision.

- They are easy, simple, accurate, low-cost useful tools for physiological studies related to the growth and development of plants.

As a main disadvantage [6] it has been pointed out that an untrustworthy equation can create biases in the analyses derived from the models; so it is necessary to take into account the moments or stages for the measurement, which must correspond with the objectives of the studies that are intended to be carried out. It must be added that the sample must cover the entire range of values that will be used in the future; otherwise, the behavior of models outside the range for which they were built would be unknown.

Several researchers have used regression techniques for the estimation of leaf area as non-destructive methods in diverse crops such as peach, plum, coffee, potato and others [2] [3] [4] [8]. Most of the investigations coincide in measuring the length and the maximum width of the leaf as determining parameters, and the relation of the product of both as the better model. However, in all cases, 
different adjustments are checked and the best is verified from the study of the coefficients of determination and the F tests for the significance of the slope, as exemplified in the following cases.

For the estimation of foliar area of vine Cabernet Sauvignon in three stages of development and subjected to different irrigation schemes, several models were assayed [10]. Different shape parameters were considered for the estimation (leaf area, perimeter, maximum length, maximum width and radial average) using image processing. Eleven prediction models were tested, concluding that the most accurate was the one that related the leaf area with the product of the length by the width without intercept $\left(\left(\right.\right.$ Leaf area $=\beta\left(\right.$ Length ${ }^{*}$ Width $\left.)\right)$.

Leaf area in jojoba seedlings (Simmondsia chinensis (Link.) CE Schneider) was estimated from linear regression equations which related the product of the length by the width of the leaf, comparing the proportion of leaves with acute and obtuse apex [5]. From these equations the coefficient $\mathrm{K}$ for the estimation of the leaf area was determined $\left(\mathrm{K}=\left((\right.\right.$ Estimated area $) /\left(\right.$ Length ${ }^{\star}$ Width $\left.\left.)\right)\right)$ and the means of each one of the groups were compared, not finding significant differences between them.

The evaluation of allometric models for the estimation of the foliar area in vines (Vitis vinifera L. genotypes), looking for simpler models showed that simple regression models based on the length of the leaf achieve good results but sacrifice accuracy; thus, the estimation of the area depending on the product of the length by the width of the leaf is suggested [11].

Digital image processing and regression adjustment have been used for constructing models to determine the foliar area of the Persian walnut (Juglans regia L.), also recommending the use of linear models that relate the leaf area with the product of the length by the width of the leaf [12].

Similar results were obtained in plants of Vernonia ferruginea [13] where after testing different models it was confirmed that the product of the length by the width of the leaf fits the regression models for the estimation of foliar area.

More recent works [14] [15] [16] [17] also suggest the use of these models for estimating the foliar area in different plant species. The comparison of different regression models with easy-to-measure parameters such as the length of the leaf and its maximum width, as well as the relationship between both parameters, especially between the product of the length by the width, coincide in all cases.

In pepper (Capsicum annuum L.), the estimation of the leaf area by mathematical methods has been reported by several authors, and has been recently reviewed [7]. However, the realization of studies of this type is still valid for the particular conditions of agroecosystems. The objective of this work was to estimate the leaf area in pepper under nursery conditions, in the environmental conditions of the coast of Ecuador.

\section{Materials and Methods}

The evaluations were carried out on plants of pepper (Capsicum annuum $\mathrm{L}$. 
hybrid Salvador), growing in a nursery at the Experimental Campus La Teodomira, located in the parish of Lodana, Santa Ana, province of Manabí, Ecuador, in 2016. The process of estimating the leaf area was divided into three steps: the first was sampling, which was executed in two stages of development of the pepper plants (initiation of flowering and flowering-fructification); 100 physiologically mature leaves (two leaves/plant) were randomly selected in each of the stages of development, in 50 plants chosen by the zigzag sampling technique.

In the second step, for each sampled leaf the length and maximum width (in centimeters) were determined with a millimeter ruler.

The third step was to develop a procedure for the calculation of the foliar area in the collected leaves, which was based on a digitalization of the image of each leaf within a figure of easy calculation of the area (rectangle) as represented in Figure 1.

The area of the rectangle (Rectangle Area $=a^{*} b$ ) was related to the leaf area, based on the difference of pixels of different colors and the percentage they represent within the area of the rectangle (Foliar Area $=\%$ Black pixels ${ }^{\star}$ Rectangle Area).

For the calculation, a software was developed to carry on the binarization process of the image, which consists of analyzing each pixel and defining it in two colors, white or black. We used the Java programming language that is part of a large set of free tools [18]. The first steps before the application of the binarization filters that serve to facilitate the subsequent operations are: acquisition, exportation, development, conversion, transformation, scaling and binarization [19].

A code was used, with libraries that allow the handling of images, improving and adapting them to the needs. The system establishes which pixel has a value of 255, determining it with a white color and which pixel has a value of zero, determining it with a black color. For the case of images having different colors, a threshold value (200) was used, which was compared with an average obtained from the value of the pixel of each of the three basic colors (RGB). If this value was lower than the threshold value, it was assumed that the color is black,

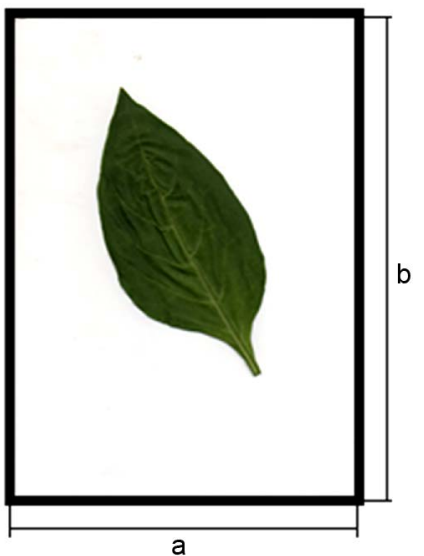

Figure 1. Digitization of the leaf inside a rectangle with known sides ( $a$ and $b$ ). 
otherwise it was set as white (it should be noted that each pixel contains a variation of 256 colors). Another aspect considered was the size of the image in pixels, multiplying the width by the length and obtaining the total number of pixels (area of the rectangle).

The total number of white pixels was counted and divided for the total of pixels to obtain the percentage of free area. The total number of black pixels was divided for the total of pixels, obtaining the percentage of the area of each leaf.

In this example (Figure 2) a binarized image is shown, which has a width of 8 pixels and a length of 8 pixels, for a total area of 64 pixels. The black pixels corresponding to the leaf area (24) are counted, giving that the leaf area is $37.5 \%$ of the rectangle area.

$$
\begin{aligned}
\frac{\text { black pixels }}{\text { total pixels }} * 100 *(\text { rectangle area }) & =\left(\frac{24}{64}\right) * 100 *(a * b) \\
& =37.5 \% *(a * b)
\end{aligned}
$$

To facilitate the use of the application, a graphical interface was developed (Figure 3), where in a window default values and the icons to execute the binarization process are presented. The shown value (200) is the threshold to assume if the pixel is set as white or black. After their definition as white or black they are counted to have the total pixels, and with this proportion the actual leaf area

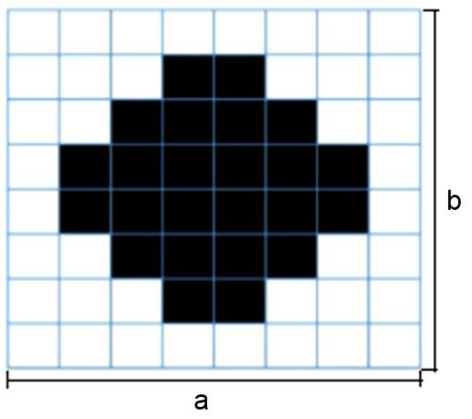

Figure 2. Example of binarized image.

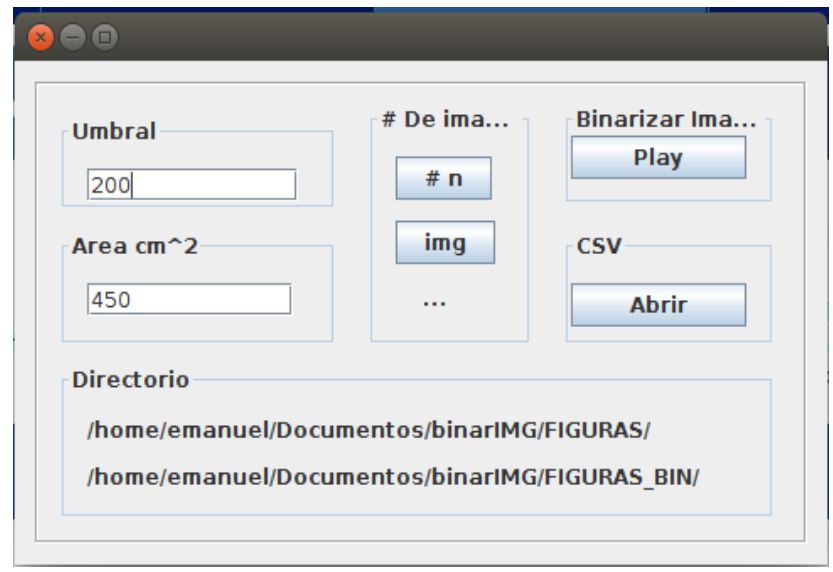

Figure 3. Interface of the software developed for the binarization process. 
is calculated by multiplying the percentage by $450 \mathrm{~cm}^{2}$ (area of the rectangle pre-established in the digitization process). In addition, the directories of the non-binarized and binarized images are also accesible.

where:

\#n: Number of images to be binarized

Img: Number of binarized images

Play: Start of the digitalization

CSV: Generates a standard sheet of comma-delimited format, which can be opened from an Excel spreadsheet and includes all the sorted names of the leaves with their respective area (Figure 4).

Once the areas of leaves were calculated, a descriptive analysis of the variables studied was carried out (length, maximum width and leaf area). Later, a comparison between the mean values in the two sampling stages was conducted, in order to detect possible homogeneity between both moments. For this analysis t-tests were made for comparison of means, as well as box and whisker graphics.

Then, several regression models were tested for the estimation of the leaf area according to the explanatory variables in each of the sampling stages. The models (linear, inverse, quadratic, cubic, power and exponential) were tested for each of these variables (length and maximum width of the leaf) as well as for the product of the length by the maximum width (length * width).

The selection of the best model for each stage was based on the slope significance tests (F Test) and the best determination coefficient $\left(R^{2}\right)$ as it has been recommended [14] [15] [16] [17] in addition to the suggested residue analysis [20].

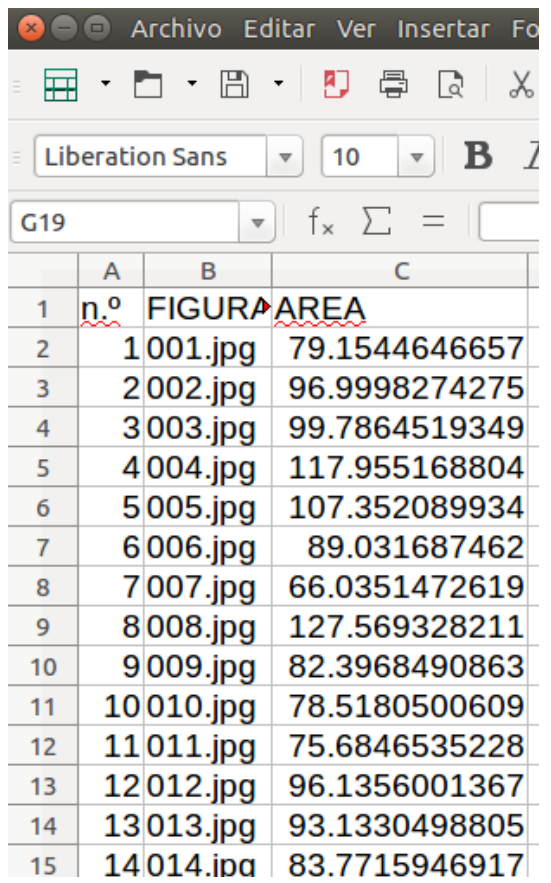

Figure 4. Excel output table with calculation of the leaf area. 


\section{Results}

Table 1 shows a descriptive characterization of the samples taken in each of the sampling stages. As can be observed, there is less variability in the behavior of the leaf area and the width of the leaves in the flowering-fructification stage, but not in the length of the leaves, where the coefficient of variation was lower in the stage of initiation of flowering.

In Table 2 and Figure 5, comparisons made between the three parameters studied in each stage are shown. Significant differences between the two stages in each of the parameters were found, using a t-test for the comparison of means with heterogeneous variances -as suggested by the Levene test for leaf area- and homogeneous in the parameters length and maximum width of the leaf ( $\alpha=$ 0.05).

The use of six models (linear, inverse, quadratic, cubic, power and exponential) for the independent variables length of the leaf (L), maximum width of leaf (W) and product of the length by the width $\left(\mathrm{L}^{*} \mathrm{~W}\right)$ and as dependent variable the leaf area (LA) in the two stages of sampling (initiation of flowering and flowering-fruiting) led to the test of 36 models, 18 for each stage. Results are shown in Table 3.

Using the criterion of the highest $\mathrm{R}^{2}$ in addition to the analysis of the residues (Figure 6 and Figure 7), the model No. 6 (Quadratic model of the leaf area

Table 1. Description of the samples taken in each of the experimental stages. Minimum value (Min), Maximum value (Max), Average value (Mean), Standard error of the mean (SE) and Coefficient of variation (CV).

\begin{tabular}{ccccccc}
\hline Stage & Parameter & Min & Max & Mean & SE & CV \\
\hline \multirow{2}{*}{$\begin{array}{c}\text { Initiation } \\
\text { of flowering }\end{array}$} & LA & $72.91 \mathrm{~cm}^{2}$ & $200.66 \mathrm{~cm}^{2}$ & $129.46 \mathrm{~cm}^{2}$ & $2.826 \mathrm{~cm}^{2}$ & $21.83 \%$ \\
& $\mathrm{~L}$ & $15.70 \mathrm{~cm}$ & $25.50 \mathrm{~cm}$ & $20.83 \mathrm{~cm}$ & $0.232 \mathrm{~cm}$ & $11.16 \%$ \\
$\begin{array}{c}\text { Flowering- } \\
\text { fructification }\end{array}$ & LA & $68.15 \mathrm{~cm}^{2}$ & $190.47 \mathrm{~cm}^{2}$ & $117.91 \mathrm{~cm}^{2}$ & $2.256 \mathrm{~cm}^{2}$ & $19.13 \%$ \\
& $\mathrm{~L}$ & $14.80 \mathrm{~cm}$ & $25.30 \mathrm{~cm}$ & $19.59 \mathrm{~cm}$ & $0.224 \mathrm{~cm}$ & $11.45 \%$ \\
\hline
\end{tabular}

LA: Leaf area; L: Length; W: Maximum width; $\mathrm{N}=100$.

Table 2. Comparison of the means of each of the parameters in the two sampling stages, Average value (Mean), Standard error of the mean (SE), Statistic of Levene (F), Statistic $t$ of comparison of means of independent samples ( $t$ ), Significance of the tests (Sig).

\begin{tabular}{|c|c|c|c|c|c|c|c|c|}
\hline \multirow{3}{*}{ Parameter } & \multicolumn{4}{|c|}{ Stage } & \multirow{2}{*}{\multicolumn{2}{|c|}{$\begin{array}{c}\text { Statistic of } \\
\text { Levene }\end{array}$}} & \multirow{2}{*}{\multicolumn{2}{|c|}{ T test }} \\
\hline & \multicolumn{2}{|c|}{ Initiation of flowering } & \multicolumn{2}{|c|}{ Flowering-fructification } & & & & \\
\hline & Mean & SE & Mean & SE & $\mathrm{F}$ & Sig & $\mathrm{t}$ & Sig \\
\hline LA & $129.46 \mathrm{~cm}^{2}$ & $2.826 \mathrm{~cm}^{2}$ & $117.91 \mathrm{~cm}^{2}$ & $2.256 \mathrm{~cm}^{2}$ & 4.602 & $0.033\left(^{\star}\right)$ & 3.194 & $0.002^{* *}$ \\
\hline $\mathrm{L}$ & $20.83 \mathrm{~cm}$ & $0.232 \mathrm{~cm}$ & $19.59 \mathrm{~cm}$ & $0.224 \mathrm{~cm}$ & 0.091 & 0.760 (ns) & 3.81 & $0.000^{* * *}$ \\
\hline $\mathrm{W}$ & $9.67 \mathrm{~cm}$ & $0.117 \mathrm{~cm}$ & $9.20 \mathrm{~cm}$ & $0.103 \mathrm{~cm}$ & 1.020 & $0.310(\mathrm{~ns})$ & 3.00 & $0.003^{* *}$ \\
\hline
\end{tabular}

LA: Leaf area; L: Length; W: Maximum width; $\left({ }^{*}\right) \mathrm{p}<0.05 ;\left({ }^{* *}\right) \mathrm{p}<0.01 ;\left({ }^{* * *}\right) \mathrm{p}<0.001$; (ns) Non-significant; $\mathrm{N}=100$. 

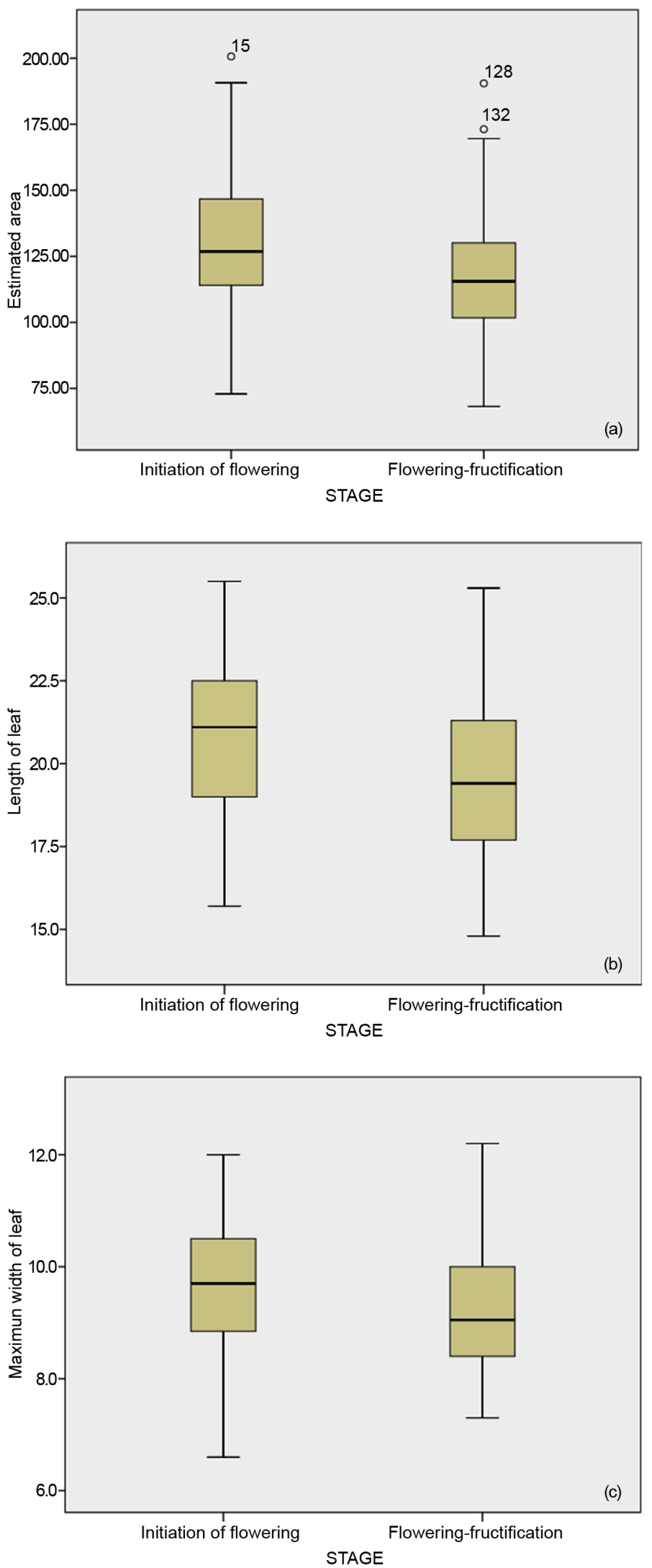

Figure 5. Comparison of the different parameters ((a)-estimated area; (b)-length of leaf; (c)-maximum width of leaf) in the two sampling stages. 
Table 3. Adjusted coefficients of the regression models, Coefficient of determination $\left(\mathrm{R}^{2}\right)$, Statistic $\mathrm{F}$ of the docima of the slope (F), Significance of the test (Sig) and Standard error of the estimate $\left(\mathrm{S}_{\mathrm{LA}}\right)$.

\begin{tabular}{|c|c|c|c|c|c|c|c|c|c|}
\hline \multirow{3}{*}{ Model } & \multirow[b]{3}{*}{ Assayed model } & \multicolumn{8}{|c|}{ Stages } \\
\hline & & \multicolumn{7}{|c|}{ Initiation of flowering } & \multirow[b]{2}{*}{$\mathrm{S}_{\mathrm{LA}}$} \\
\hline & & $\alpha$ & $\beta$ & $\delta$ & $\omega$ & $\mathrm{R}^{2}$ & $\mathrm{~F}$ & Sig & \\
\hline 1 & $\mathrm{LA}=\alpha+\beta^{\star}(\mathrm{L})$ & -98.506 & 10.946 & - & - & 0.811 & 419.75 & $* * *$ & 12.358 \\
\hline 2 & $\mathrm{LA}=\alpha+\beta^{*}(\mathrm{~W})$ & -62.822 & 9.223 & - & - & 0.842 & 520.672 & $* * *$ & 9.024 \\
\hline 3 & $\mathrm{LA}=\alpha+\beta^{*}(\mathrm{~L} * \mathrm{~W})$ & 0.361 & 0.634 & - & - & 0.953 & 1981.67 & $* * *$ & 6.166 \\
\hline 4 & $\mathrm{LA}=\alpha+\beta^{*}(\mathrm{~L})+\delta^{*}(\mathrm{~L})^{2}$ & -8.797 & 2.111 & 0.215 & - & 0.813 & 210.505 & $* * *$ & 12.354 \\
\hline 5 & $\mathrm{LA}=\alpha+\beta^{\star}(\mathrm{W})+\delta^{\star}(\mathrm{W})^{2}$ & 134.323 & -10.939 & 0.509 & - & 0.858 & 291.993 & $* * *$ & 8.601 \\
\hline 6 & $\mathrm{LA}=\alpha+\beta^{*}(\mathrm{~L} * \mathrm{~W})+\delta^{*}(\mathrm{~L} * \mathrm{~W})^{2}$ & 37.943 & 0.244 & 0.001 & - & 0.958 & 1095.73 & $* * *$ & 5.878 \\
\hline 7 & $\mathrm{LA}=\alpha+\beta^{\star}(\mathrm{L})+\delta^{\star}(\mathrm{L})^{2}+\omega^{\star}(\mathrm{L})^{3}$ & \multicolumn{8}{|c|}{ Non Significant (Multicolinearity in the model terms) } \\
\hline 8 & $\mathrm{LA}=\alpha+\beta^{\star}(\mathrm{W})+\delta^{\star}(\mathrm{W})^{2}+\omega^{\star}(\mathrm{W})^{3}$ & \multicolumn{8}{|c|}{ Non Significant (Multicolinearity in the model terms) } \\
\hline 9 & $\mathrm{LA}=\alpha+\beta^{\star}\left(\mathrm{L}^{*} \mathrm{~W}\right)+\delta^{\star}\left(\mathrm{L}^{*} \mathrm{~W}\right)^{2}+\omega^{\star}\left(\mathrm{L}^{*} \mathrm{~W}\right)^{3}$ & \multicolumn{8}{|c|}{ Non Significant (Multicolinearity in the model terms) } \\
\hline 10 & $\mathrm{LA}=\alpha+\beta /(\mathrm{L})$ & 343.649 & -4403.45 & - & - & 0.788 & 364.537 & $* * *$ & 13.074 \\
\hline 11 & $\mathrm{LA}=\alpha+\beta /(\mathrm{W})$ & 293.803 & -3402.19 & - & - & 0.801 & 393.761 & $* * *$ & 10.122 \\
\hline 12 & $\mathrm{LA}=\alpha+\beta /\left(\mathrm{L}^{\star} \mathrm{W}\right)$ & 241.632 & -21714.45 & - & & 0.88 & 718.503 & $* * *$ & 9.840 \\
\hline 13 & $\mathrm{LA}=\alpha^{*} \mathrm{~L} \wedge \beta$ & 0.547 & 1.796 & - & - & 0.824 & 460.246 & $* * *$ & 0.095 \\
\hline 14 & $\mathrm{LA}=\alpha^{\star} \mathrm{W}^{\wedge} \beta$ & 1.340 & 1.502 & - & - & 0.835 & 497.648 & $* * *$ & 0.077 \\
\hline 15 & $\mathrm{LA}=\alpha^{\star}\left(\mathrm{W}^{\star} \mathrm{L}\right)^{\wedge} \beta$ & 0.698 & 0.982 & - & & 0.953 & 1978.392 & $* * *$ & 0.049 \\
\hline 16 & $\mathrm{LA}=\alpha^{*} \beta^{\wedge} \mathrm{L}$ & 20.142 & 0.088 & - & - & 0.821 & 450.973 & $* * *$ & 0.096 \\
\hline 17 & $\mathrm{LA}=\alpha^{\star} \beta \wedge \mathrm{W}$ & 25.629 & 0.077 & - & - & 0.841 & 519.726 & $* * *$ & 0.075 \\
\hline 18 & $\mathrm{LA}=\alpha^{\star} \beta^{\wedge}\left(\mathrm{W}^{\star} \mathrm{L}\right)$ & 45.092 & 0.005 & - & & 0.948 & 1776.135 & $* * *$ & 0.052 \\
\hline \multirow{2}{*}{ Model } & & \multicolumn{7}{|c|}{ Flowering-Fructification } & \\
\hline & Assayed model & $\alpha$ & $\beta$ & $\delta$ & $\omega$ & $\mathrm{R}^{2}$ & $\mathrm{~F}$ & Sig & $\mathrm{S}_{\mathrm{LA}}$ \\
\hline 19 & $\mathrm{LA}=\alpha+\beta^{\star}(\mathrm{L})$ & -62.822 & 9.223 & - & - & 0.842 & 520.672 & $* * *$ & 9.024 \\
\hline 20 & $\mathrm{LA}=\alpha+\beta^{\star}(\mathrm{W})$ & -68.178 & 20.218 & - & - & 0.853 & 567.215 & $* * *$ & 8.703 \\
\hline 21 & $\mathrm{LA}=\alpha+\beta^{*}(\mathrm{~L} * \mathrm{~W})$ & 16.973 & 0.554 & - & - & 0.926 & 1719.216 & $* * *$ & 5.265 \\
\hline 22 & $\mathrm{LA}=\alpha+\beta^{\star}(\mathrm{L})+\delta^{*}(\mathrm{~L})^{2}$ & 134.323 & -10.939 & 0.509 & - & 0.858 & 291.993 & $* * *$ & 8.601 \\
\hline 23 & $\mathrm{LA}=\alpha+\beta^{\star}(\mathrm{W})+\delta^{\star}(\mathrm{W})^{2}$ & 74.250 & -10.398 & 1.625 & - & 0.861 & 300.442 & $* * *$ & 8.497 \\
\hline 24 & $\mathrm{LA}=\alpha+\beta^{*}(\mathrm{~L} * \mathrm{~W})+\delta^{*}(\mathrm{~L} * \mathrm{~W})^{2}$ & 41.614 & 0.287 & 0.001 & & 0.949 & 901.919 & $* * *$ & 5.148 \\
\hline 25 & $\mathrm{LA}=\alpha+\beta^{\star}(\mathrm{L})+\delta^{\star}(\mathrm{L})^{2}+\omega^{\star}(\mathrm{L})^{3}$ & \multicolumn{8}{|c|}{ Non Significant (Multicolinearity in the model terms) } \\
\hline 26 & $\mathrm{LA}=\alpha+\beta^{\star}(\mathrm{W})+\delta^{\star}(\mathrm{W})^{2}+\omega^{\star}(\mathrm{W})^{3}$ & \multicolumn{8}{|c|}{ Non Significant (Multicolinearity in the model terms) } \\
\hline 27 & $\mathrm{LA}=\alpha+\beta^{*}(\mathrm{~L} * \mathrm{~W})+\delta^{*}(\mathrm{~L} * \mathrm{~W})^{2}+\omega^{*}(\mathrm{~L} * \mathrm{~W})^{3}$ & -101.11 & 2.564 & -0.01 & $1.95 * 10^{-5}$ & 0.955 & 685.99 & $* * *$ & 4.836 \\
\hline 28 & $\mathrm{LA}=\alpha+\beta /(\mathrm{L})$ & 293.803 & -3402.195 & - & - & 0.801 & 393.761 & $* * *$ & 10.122 \\
\hline 29 & $\mathrm{LA}=\alpha+\beta /(\mathrm{W})$ & 304.4 & -1695.803 & - & - & 0.820 & 446.167 & $* * *$ & 9.622 \\
\hline 30 & $\mathrm{LA}=\alpha+\beta /(\mathrm{L} * \mathrm{~W})$ & 219.541 & -17703.3 & - & - & 0.889 & 788.774 & $* * *$ & 7.538 \\
\hline 31 & $\mathrm{LA}=\alpha^{\star} \mathrm{L} \wedge \beta$ & 1.340 & 1.502 & - & - & 0.835 & 497.648 & $* * *$ & 0.077 \\
\hline 32 & $\mathrm{LA}=\alpha^{\star} \mathrm{W}^{\wedge} \beta$ & 3.689 & 1.557 & - & - & 0.837 & 503.641 & $* * *$ & 0.076 \\
\hline 33 & $\mathrm{LA}=\alpha^{\star}\left(\mathrm{W}^{*} \mathrm{~L}\right) \wedge \beta$ & 1.402 & 0.852 & - & - & 0.931 & 1338.087 & $* * *$ & 0.049 \\
\hline 34 & $\mathrm{LA}=\alpha^{*} \beta^{\wedge} \mathrm{L}$ & 25.629 & 0.077 & - & - & 0.841 & 519.726 & $* * *$ & 0.075 \\
\hline 35 & $\mathrm{LA}=\alpha^{*} \beta^{\wedge} \mathrm{W}$ & 24.838 & 0.167 & - & - & 0.836 & 506.371 & $* * *$ & 0.076 \\
\hline 36 & $\mathrm{LA}=\alpha^{\star} \beta^{\wedge}\left(\mathrm{W}^{\star} \mathrm{L}\right)$ & 50.371 & 0.005 & - & - & 0.924 & 1196.285 & $* * *$ & 0.052 \\
\hline
\end{tabular}



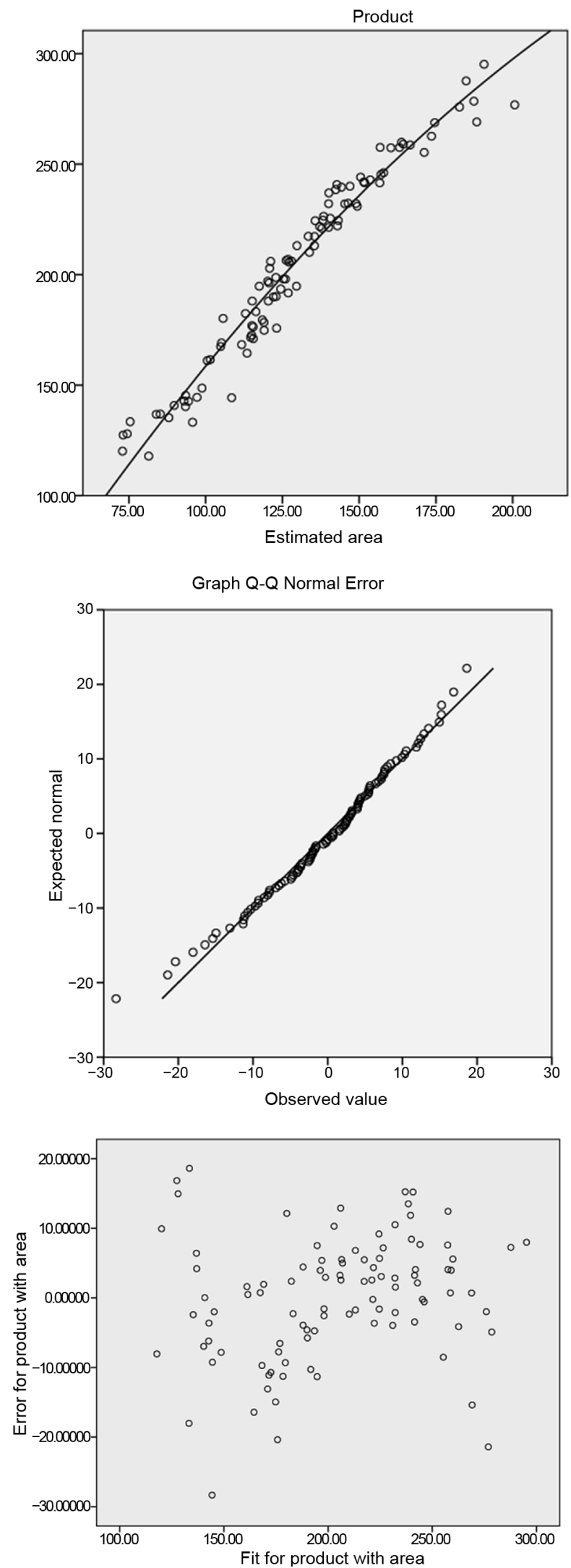

Figure 6. Dispersion diagram, Q-Q graph for normality and plotting of the resulting residues of model 6 (Quadratic) for the initiation of flowering stage. 

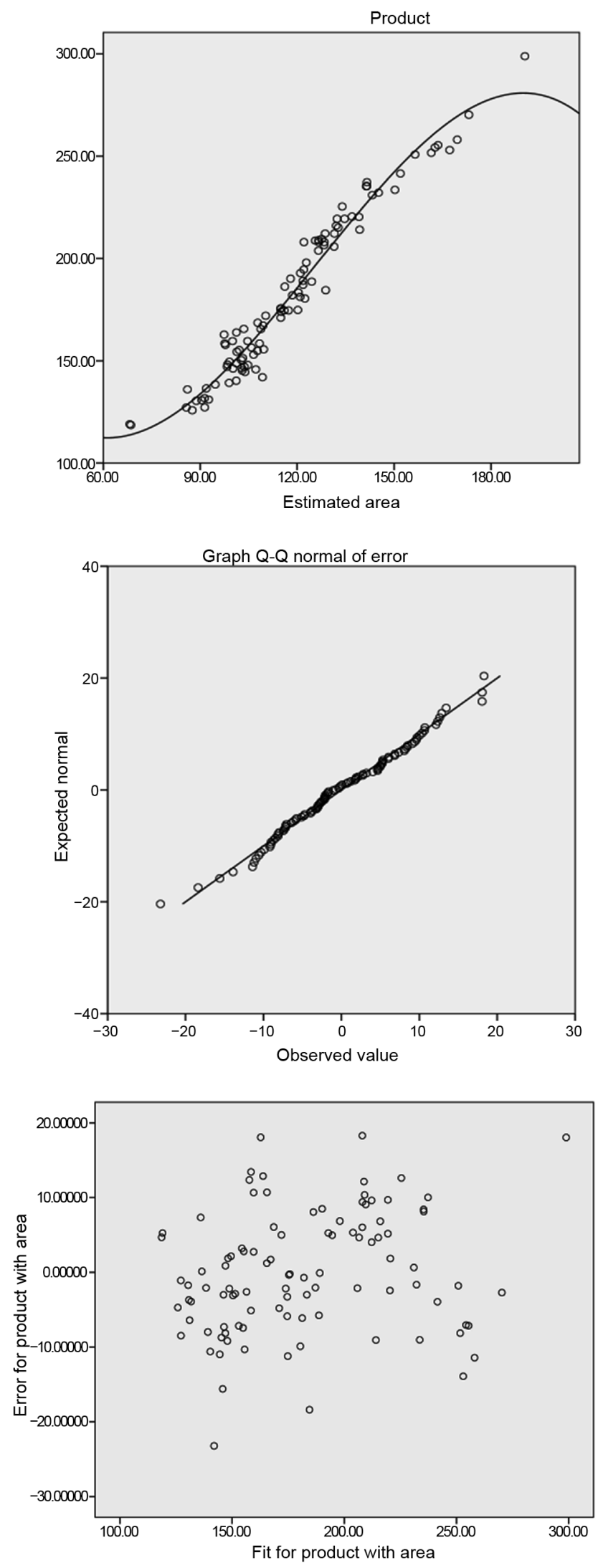

Figure 7. Dispersion diagram, Q-Q graph for normality and plotting of the resulting residues of model 27 (Cubic) for the flowering-fructification stage. 
depending on the product of the length by the width of the leaf) was selected for the initiation of flowering, and No. 27 (cubic model of the foliar area depending on the product of the length by the width of the leaf) for flowering-fructification, where:

Initiation of flowering: $\mathrm{LA}=0.244 *\left(\mathrm{~L}^{\star} \mathrm{W}\right)+0.001 *\left(\mathrm{~L}^{\star} \mathrm{W}\right)^{2}+37.9943$

$\mathrm{R}^{2}=0.958 \mathrm{~S}_{\mathrm{LA}}=.878$

Flowering-fructification: $\mathrm{LA}=2.564 *(\mathrm{~L} * \mathrm{~W})-0.01 *(\mathrm{~L} * \mathrm{~W})^{2}+1.95 * 10^{(-5)}$

* $(\mathrm{L} * \mathrm{~W})^{3}-101.11$

$\mathrm{R}^{2}=0.955 \mathrm{~S}_{\mathrm{LA}}=4.836$

\section{Discussion}

Under nursery conditions for Capsicum annum L. hybrid Salvador, the variables length and maximum width of leaf guarantee high precision in the estimation of the foliar area, based on models showing coefficients of determination $\left(\mathrm{R}^{2}\right)$ greater than 0.9 and achieving the best results when the product (length ${ }^{*}$ width) is used as an explanatory variable.

In both stages of growth and development (initiation of flowering and flowering-fructification) 30 of the 35 equations showed high values in the coefficients of determination (amplitude of variation of $\mathrm{R}^{2}$ between 0.877 and 0.93 with $\mathrm{p}<0.0001$ ). This result shows that for Capsicum annuum $\mathrm{L}$. is also valid that models using the measures of length, maximum width of the leaves and product of the multiplication of the two foliar attributes can provide high precision estimates for the fast, accurate and economic determination of the foliar area in physiological, biological, environmental and agronomic investigations.

It is worth analyzing the implication of the use of more practical models and the sacrifice that this entails in their accuracy, which highlights the possible use of model 3 in the initiation of flowering stage: $\mathrm{LA}=0.634^{*}\left(\mathrm{~L}^{*} \mathrm{~W}\right)+0.361\left(\mathrm{R}^{2}=\right.$ $\left.0.953, \mathrm{~S}_{\mathrm{LA}}=6.166\right)$. This model gains in practicality because it is a simple linear model and only sacrifices $0.5 \%$ in the percentage of errors explained with the regression.

Also, in the flowering-fructification stage the model 24 (polynomial grade 2) would be useful: $\mathrm{LA}=0.287 *(\mathrm{~L} * \mathrm{~W})+0.001 *(\mathrm{~L} * \mathrm{~W})^{2}+41.614\left(\mathrm{R}^{2}=0.949\right.$; $\left.\mathrm{S}_{\mathrm{LA}}=5.148\right)$. In this model $0.6 \%$ is sacrificed in the percentage of errors explained with the regression with respect to the best fit model.

In both cases, the sacrifice is not highly significant, so the inclusion of both models in the estimation process can be assessed in order to gain practicality in its application.

The main advantage of the proposed method is that the measurements of the variables can be done in vivo, with a simple instrument (millimeter rule) and without the need of destructive sampling, which has been useful for other species. Besides, costs are reduced and the possibility of studying the evolution of the parameters is clearly available [1] [3]-[8]. 


\section{References}

[1] Cabezas-Gutiérrez, M., Peña, F., Duarte, H.W., Colorado, J.F. and Lora, L. (2009) Un modelo para la estimación del área foliar en tres especies forestales de forma no destructiva. Revista U.D.C.A. Actualidad \& Divulgación Científica, 12, 121-130.

[2] Casierra F., Zapata, V. and Cutler, J. (2017) Comparación de métodos directos e indirectos para la estimación del área foliar en duraznero (Prunus persica) y ciruelo (Prunus salicina). Revista Colombiana de Ciencias Hortícolas, 11, 30-38.

[3] Interdonato, R., Romero, J.I., Bas Nahas, S.S., Roberti, J.O., Rodríguez Rey, J.A. and Romero, E.R. (2015) Estimación no destructiva del área foliar por planta en sorgos bioenergéticos. Revista Agronómica del Noroeste Argentino, 35, 51-53.

[4] Jerez, E., Martín, R. and Díaz, Y. (2014) Estimación de la superficie foliar en dos variedades de papa (Solanum tuberosum L.) por métodos no destructivos. Cultivos Tropicales, 35, 57-61.

[5] Khan, D., Javed Zaki, M. and Murtaza Abbas, S. (2015) Leaf Area Estimation in Jojoba (Simmondsia chinensis (Link.) C. E. Schneider) Seedlings. International Journal of Biology and Biotechnology, 12, 667-674.

[6] Khan, F.A., Banday, F.A., Narayan, S., Khan, F.U. and Bhat, S.A. (2016) Use of Models as Non-Destructive Method for Leaf Area Estimation in Horticultural Crops. IRA-International Journal of Applied Sciences, 4,162-180. https://doi.org/10.21013/jas.v4.n1.p19

[7] Montoya, E. C., Hernández, J.D, Unigarro, C.A. and Flóres, C.P. (2017) Estimación del área foliar en café variedad Castillo ${ }^{\circledR}$ a libre exposición y su relación con la producción. Revista Cenicafé, 68, 55-61.

[8] Razquin, C.J., Maddonni, G.A. and Vega, C.R.C. (2017) Estimación no destructiva del área foliar en plantas individuales de maíz (Zea mays L.) creciendo en canopeos. Agriscientia, 34, 27-38.

[9] Kandiannan, K., Parthasarathy, U., Krishnamurthy, K.S., Thankamani, C.K. and Srinivasan, V. (2009) Modeling Individual Leaf Area of Ginger (Zingiber officinale Roscoe) Using Leaf Length and Width. Scientia Horticulturae, 120, 532-537. https://doi.org/10.1016/j.scienta.2008.11.037

[10] Tsialtas, J.T., Koundouras, S. and Zioziou, E. (2008) Leaf Area Estimation by Simple Measurements and Evaluation of Leaf Area Prediction Models in Cabernet-Sauvignon Grapevine Leaves. Photosynthetica, 46, 452-456. https://doi.org/10.1007/s11099-008-0077-x

[11] Buttaro, D., Rouphael, Y., Rivera, C.M., Colla, G. and Gonnella, M. (2015) Simple and Accurate Allometric Model for Leaf Area Estimation in Vitis vinifera L. Genotypes. Photosynthetica, 53, 342-348. https://doi.org/10.1007/s11099-015-0117-2

[12] Keramatlou, I., Sharifani, M., Sabouri, H., Alizadeh, M. and Kamkar, B. (2015) A Simple Linear Model for Leaf Area Estimation in Persian walnut (Juglans regia L.). Scientia Horticulturae, 184, 36-39. https://doi.org/10.1016/j.scienta.2014.12.017

[13] Souza, M.C. and Amaral, C.L. (2015) Non-Destructive Linear Model for Leaf Area Estimation in Vernonia ferruginea Less. Brazilian Journal of Biology, 75, 152-156. https://doi.org/10.1590/1519-6984.09813

[14] Kumar, J.S., More, S.J., Ravi, V., Byju, G. and George, J. (2016) Leaf Area Estimation in Yam Bean (Pachyrrhizus erosus L.) using Linear Measurement of Leaf Parameters. Journal of Root Crops, 42, 86-89.

[15] Lakitan, B., Widuri, L.I. and Meihana, M. (2017) Simplifying Procedure for a Non-Destructive, Inexpensive, Yet Accuratetrifoliate Leaf Area Estimation in Snap Bean (Phaseolus vulgaris). Journal of Applied Horticulture, 19, 15-21. 
[16] Walia, S. and Kumar, R. (2017) Development of the Nondestructive Leaf Area Estimation Model for Valeriana (Valeriana jatamansi Junes). Communications in Soil Science and Plant Analysis, 48, 83-91. https://doi.org/10.1080/00103624.2016.1253723

[17] Almehemdi, A.F., Mhidi, U.H. and Almarie, A.A. (2017) Estimation Leaf Area Model and Growth Performance of Buckwheat under Iraqi Environmental Conditions. Journal of Animal and Plant Sciences, 27, 1665-1670.

[18] Deitel, H.M. and Deitel, P.J. (2004) Cómo programar en Java. 5th Edition, Pearson Educación, México.

[19] Magro, R. (2013). Binarización de imágenes digitales y su algoritmia como herramienta aplicada a la ilustración entomológica. Boletín de la Sociedad Entomológica Aragonesa, 53, 443-464.

[20] Montgomery, D.C. (2013) Diseño y análisis de experimentos. 2nd Edition, Editorial Limusa Wiley, México. 